\title{
Overview and summary of the Spread F Experiment (SpreadFEx)
}

\author{
D. C. Fritts ${ }^{1}$, M. A. Abdu ${ }^{2}$, B. R. Batista ${ }^{2}$, I. S. Batista ${ }^{2}$, P. P. Batista ${ }^{2}$, R. Buriti ${ }^{3}$, B. R. Clemesha ${ }^{2}$, T. Dautermann ${ }^{4}$, \\ E. R. de Paula ${ }^{2}$, B. J. Fechine ${ }^{2}$, B. G. Fejer ${ }^{5}$, D. Gobbi ${ }^{2}$, J. Haase ${ }^{4}$, F. Kamalabadi ${ }^{6}$, E. A. Kherani ${ }^{2}$, B. Laughman ${ }^{1}$, \\ P. P. Lima ${ }^{3}$, H.-L. Liu ${ }^{7}$, A. Medeiros ${ }^{3}$, P.-D. Pautet ${ }^{5}$, D. M. Riggin ${ }^{1}$, F. S. Rodrigues ${ }^{8}$, F. São Sabbas ${ }^{2}$, J. H. A. Sobral ${ }^{2}$,

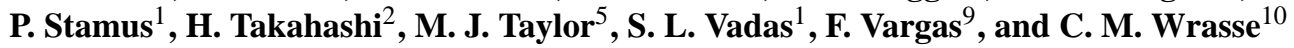 \\ ${ }^{1}$ NorthWest Research Associates, CoRA Division, Boulder, CO, USA \\ ${ }^{2}$ Instituto Nacional de Pesquisas Espaciais (INPE), São José dos Campos, Brazil \\ ${ }^{3}$ Universidade Federal de Campina Grande, Campina Grande, Paraiba, Brazil \\ ${ }^{4}$ Purdue University, West Lafayette, IN, USA \\ ${ }^{5}$ Utah State University, Logan, UT, USA \\ ${ }^{6}$ University of Illinois, Urbana, IL, USA \\ ${ }^{7}$ National Center for Atmospheric Research, Boulder, CO, USA \\ ${ }^{8}$ Cornell University, Ithaca, NY, USA \\ ${ }^{9}$ Intelekto Consultancy, São Paulo, Brazil \\ ${ }^{10}$ Instituto Nacional de Pesquisas Desenvolvimento, UNIVAP, São José dos Campos, Brazil
}

Received: 21 April 2008 - Revised: 20 October 2008 - Accepted: 4 May 2009 - Published: 11 May 2009

\begin{abstract}
We provide here an overview of, and a summary of results arising from, an extensive experimental campaign (the Spread F Experiment, or SpreadFEx) performed from September to November 2005, with primary measurements in Brazil. The motivation was to define the potential role of neutral atmosphere dynamics, specifically gravity wave motions propagating upward from the lower atmosphere, in seeding Rayleigh-Taylor instability (RTI) and plasma bubbles extending to higher altitudes. Campaign measurements focused on the Brazilian sector and included ground-based optical, radar, digisonde, and GPS measurements at a number of fixed and temporary sites. Related data on convection and plasma bubble structures were also collected by GOES 12, and the GUVI instrument aboard the TIMED satellite.

Initial results of our SpreadFEx analyses are described separately by Fritts et al. (2009). Further analyses of these data provide additional evidence of 1) gravity wave (GW) activity near the mesopause apparently linked to deep convection predominantly to the west of our measurement sites, 2) small-scale GWs largely confined to lower altitudes, 3) larger-scale GWs apparently penetrating to much higher altitudes, 4) substantial GW amplitudes implied by digisonde electron densities, and 5) apparent influences of these perturbations in the lower F-region on the formation of equatorial spread F, RTI, and plasma bubbles extending to much
\end{abstract}

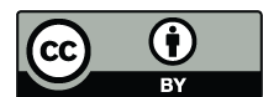

Correspondence to: D. C. Fritts (dave@cora.nwra.com) higher altitudes. Other efforts with SpreadFEx data have also yielded 6) the occurrence, locations, and scales of deep convection, 7) the spatial and temporal evolutions of plasma bubbles, 8) 2-D (height-resolved) structures in electron density fluctuations and equatorial spread $\mathrm{F}$ at lower altitudes and plasma bubbles above, and 9) the occurrence of substantial tidal perturbations to the large-scale wind and temperature fields extending to bottomside F-layer and higher altitudes. Collectively, our various SpreadFEx analyses suggest direct links between deep tropical convection and large $\mathrm{GW}$ perturbations at large spatial scales at the bottomside F-layer and their likely contributions to the excitation of RTI and plasma bubbles extending to much higher altitudes.

Keywords. Ionosphere (Ionosphere-atmosphere interactions) - Meteorology and atmospheric dynamics (Thermospheric dynamics; Waves and tides)

\section{Introduction}

Plasma instabilities, RTI, and their finite-amplitude responses at the bottomside F-layer and above are of considerable current scientific interest in the ionospheric community. Strong equatorial spread F (ESF) and flux tube-aligned plasma depletions (or plasma bubbles) arise during the prereversal enhancement (PRE) of the zonal electric field when upward $\boldsymbol{E} \times \boldsymbol{B}$ plasma drifts elevate the F-layer sufficiently for RTI initiation (Heelis et al., 1974; Fejer et al., 1999). RTI

Published by Copernicus Publications on behalf of the European Geosciences Union. 
is believed to be responsible for these plasma instabilities, and nonlinear RTI growth often causes these plasma bubbles to rise to the topside ionosphere, where well- developed bubbles may attain apex heights of $\sim 1000-1500 \mathrm{~km}$. Plasma bubbles penetrate to high altitudes on only $\sim 30$ to $60 \%$ of nights, however. They are also apparently uncorrelated at closely spaced longitudes, but may share seeding conditions, and exhibit seasonal, solar-cycle, geographic, and geomagnetic dependencies suggestive of neutral atmosphere and solar influences (McClure et al., 1977; Sobral et al., 1980a, b, 2002; Mendillo and Tyler, 1983; Abdu et al., 1992; Aggson et al., 1992; McClure et al., 1998; Fejer et al., 1999; Sobral et al., 2001; Hysell and Burcham, 2002; Rodrigues et al., 2003; Stolle et al., 2006). In particular, geographic occurrence of ESF appears to be correlated with regions of enhanced equatorial convection (McClure et al., 1998), while increasing solar flux is correlated with greater PREs of plasma drift, earlier ESF seeding and irregularity appearance, and higher initial altitudes (Hysell and Burcham, 2002).

Geographic variability, solar cycle dependence, and the spatial scales at which plasma bubbles arise are all potentially indications of the influences of neutral atmosphere dynamics on plasma instability processes at the bottomside Flayer. Indeed, they all indicate a potential role for gravity waves (GWs) arising from sources in the lower atmosphere or the mesosphere and lower thermosphere (MLT) in providing horizontal and vertical wind, neutral and plasma density, and polarization electric field perturbations contributing to plasma instability growth rates. The potential for GW effects has been recognized for many years, and has provided the motivation for various modeling and theoretical studies (Woodman and LaHoz, 1976; Klostermeyer, 1978; Anderson et al., 1982; Valladares et al., 1983; Kelley, 1989; Hysell et al., 1990; Huang et al., 1993; Huang and Kelley, 1996a, b, c; Sekar and Kelley, 1998: Taylor et al., 1998). For example, GW density or velocity perturbations of a few $\%$ are a critical seed element in all of the models that have sought to describe RTI and plasma bubble growth and morphology. To date, however, there has been no definitive proof, from observations, modeling, or theory, that GWs do provide a key element in seeding RTI and the plasma bubbles that penetrate to much higher altitudes.

There is compelling evidence, however, that deep convection is a major source of GWs having sufficiently large horizontal and vertical wavelengths, horizontal phase speeds, and vertical group velocities to penetrate efficiently to MLT altitudes and above (Taylor and Hapgood, 1988; Piani et al., 2000; Tsuda et al., 2000; Lane et al., 2001; Lane and Clark, 2002; Sentman et al., 2003; Vadas and Fritts, 2003, $2005,2006,2009$ ) and that lower atmosphere sources remain competitive with auroral sources even at very high altitudes (Hocke and Schlegel, 1996; Fritts and Vadas, 2008, hereafter FV08). There is persuasive evidence that GWs having large spatial scales and high frequencies routinely contribute neutral and plasma perturbations extending to the bot- tomside F-layer and above (Oliver et al., 1997; Djuth et al., 1997, 2004; Livneh et al., 2007; Earle et al., 2008; Vadas and Nicolls, 2008). There is also evidence that horizontal and vertical wind and neutral and plasma density perturbations at bottomside F-layer altitudes may be significant (Earle et al., 2008; Abdu et al., 2009; FV08; Fritts et al., 2008, 2009, hereafter F08 and F09; Kamalabadi et al., 2009). We note that anticipated arrival times at the bottomside F-layer of large-amplitude GWs arising from tropical convection are up to $\sim 1$ to $2 \mathrm{~h}$ after maximum late afternoon convective activity (Vadas and Fritts, 2003; FV08) and coincide closely with early evening times of strong ESF and bubble onset (Swartz and Woodman, 1998). But it is also apparent that GWs are unlikely to act alone at the bottomside F-layer, as tidal wind and temperature perturbations may likewise be very significant at bottomside F-layer altitudes, and will have major impacts on GW propagation and refraction at the altitudes where they induce large changes in the GW propagation environment. Indeed, several studies suggest that tidal winds normal to the magnetic field may play a role in RTI and plasma bubble initiation (see Meriwether et al., 2008; F08; F09). Here, we generalize these arguments and suggest that GW and tidal perturbations conspire to yield correlations among neutral and plasma perturbations at the bottomside Flayer that potentially enhance all of the perturbation fields expected to increase plasma instability growth rates simultaneously (F08; Abdu et al., 2009; Kherani et al., 2009).

The Spread F Experiment (SpreadFEx) was designed to provide the needed neutral atmosphere and ionosphere measurements, and the necessary theoretical and modeling support, to link 1) the GWs arising from deep tropical convection, 2) indications of GW amplitudes, scales, and propagation directions in airglow measurements in the MLT, 3) neutral and plasma perturbations at bottomside F-layer altitudes, and 4) plasma bubbles seen to penetrate to high altitudes. Our efforts to find this "smoking gun" of compelling evidence of the role of neutral atmosphere GWs in plasma instabilities, RTI, and plasma bubble seeding, and to understand general neutral and plasma dynamics and their coupling at equatorial latitudes more closely, are the basis for the various papers in this SpreadFEx special issue. Our purposes in this paper are to provide an overview of the SpreadFEx measurement campaign, to introduce the various papers in this special issue that deal with individual components of our various analyses in much greater detail, and to summarize the implications for potential GW seeding of plasma instabilities, RTI, and plasma bubbles in the equatorial ionosphere that are suggested by our various research results. In all cases, however, the reader is encouraged to see the more specific topical papers for more quantitative details and results not included here. An overview of the SpreadFEx campaign design and measurements is provided in Sect. 2. Successive sections introduce and summarize the contributions of the various papers in this special issue addressing 1) convective activity, locations, and intensities, 2) GW occurrence, 
amplitudes, scales, and propagation directions, 3) GW propagation and dissipation theory, 4) plasma perturbations in the F-layer, 5) GW and tidal perturbations at the bottomside F-layer and their potential influences on plasma instability growth rates, and 6) observational and modeling studies of mesospheric bores not directly related to our SpreadFEx goals, but enabled by the data obtained during our measurement campaign.

\section{Overview of the spread F experiment (SpreadFEx)}

Our goal in SpreadFEx was to perform observational and modeling studies aimed at quantifying the potential roles of GWs in seeding plasma instabilities and RTI at the bottomside F-layer and plasma bubbles penetrating to higher altitudes. Given the statistical links of plasma bubbles to tropical convection, we designed an experiment aimed at providing sensitivity to both neutral atmosphere responses to deep convection and plasma instabilities and structures at higher altitudes. We chose to perform our experiment in Brazil, where colleagues at Instituto Nacional de Pesquisas Espaciais (INPE) have extensive instrumentation for, and experience with, studies of the equatorial neutral atmosphere and ionosphere. The specific role envisioned for GWs was via generation by deep convection, propagation into the thermosphere and ionosphere (TI) (with amplitude growth due to decreasing density and refraction and filtering by large-scale winds), attainment of large GW horizontal and vertical wind, temperature, and neutral and plasma density perturbations at the bottomside F-layer, and GW and tidal modulation of RTI growth rates and potential seeding of plasma bubbles extending to higher altitudes. This scenario is depicted in Fig. 1. Specific questions motivating the design of our measurement campaign and our subsequent analysis, modeling, and theoretical efforts include

1. Do GWs play a significant role in seeding plasma instabilities at the bottomside F-layer and plasma bubbles at greater altitudes?

2. How do GW perturbations to the bottomside F-layer alter the seeding conditions conducive to initial plasma instabilities and RTI?

3. If GWs are an important component in plasma instabilities and bubble seeding, what are the geophysical parameters controlling their influences?

4. Are GW roles in plasma instability and bubble seeding sufficiently correlated with other measured geophysical parameters to allow their parameterization?

To begin to address these questions, we designed a research program composed of three components: an experimental campaign, a series of analysis efforts, and supporting modeling and theoretical studies. The experimental campaign

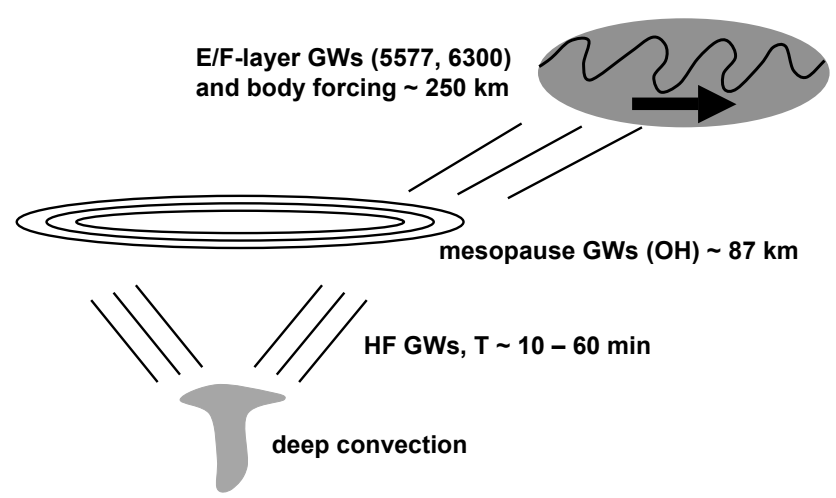

Fig. 1. Cartoon of GWs arising from deep convection, their propagation to higher altitudes, and their potential contributions to plasma perturbations, instabilities, and plasma bubble seeding. Slanted lines denote GW phase surfaces in a 2-D plane, rings denote airglow signatures near the mesopause, and the shaded region denotes the bottomside F-layer with plasma density, velocity, and/or polarization electric field perturbations accompanying GW neutral perturbations. The bold arrow indicates the body forcing accompanying GW dissipation at high altitudes.

included two measurement sequences during "moon down" conditions from 25 September to 10 October and from 23 October to 8 November 2005. Our initial intent was to coordinate these measurements with initial data collection by the C/NOFS satellite, but successive launch delays caused us to go forward as a "stand-alone" campaign. SpreadFEx measurement sequences employed a suite of airglow cameras, VHF and meteor radars, digisondes, and GPS receivers at a number of fixed and temporary sites in Brazil. Correlative measurements were also performed with the Global UltraViolet Imager (GUVI) instrument aboard the Thermosphere, Ionosphere, Mesosphere, Energetics and Dynamics (TIMED) satellite. Additional correlative opportunities were made possible through routine data collection by the Jicamarca Radio Observatory (JRO) in Peru and continuous measurements by the Geostationary Operational Environmental Satellite (GOES) 12 satellite. GUVI measured electron densities via $1356 \AA$ A emissions extending from $\sim 100$ to $600 \mathrm{~km}$ on several days coincident with our SpreadFEx ground-based measurements, while GOES 12 yielded continuous data on the locations, scales, and intensities of tropical convection throughout our measurement sequences. JRO data, while potentially useful for correlative studies, have not been employed for SpreadFEx studies to date. The second and third components of the SpreadFEx research program, our various SpreadFEx data analyses and the supporting modeling and theoretical efforts, have provided the basis for the majority of the results reported in this special issue.

Our SpreadFEx measurement campaign was performed in central and eastern Brazil in collaboration with colleagues at INPE in Brazil, Utah State University (USU), and Purdue University (PU). INPE optical and radar instrumentation 
Table 1. Instrumentation at the fixed INPE and temporary SpreadFEx measurements sites employed for our experiment. GPS were also available at $\sim 20$ other locations in Brazil.

\begin{tabular}{lcccccccc}
\hline Site & $\begin{array}{c}\text { Geogr. } \\
\text { latitude }\end{array}$ & $\begin{array}{c}\text { Geogr. } \\
\text { longitude }\end{array}$ & $\begin{array}{c}\text { Magnetic } \\
\text { latitude }\end{array}$ & $\begin{array}{c}\text { airglow } \\
\text { imager }\end{array}$ & $\begin{array}{c}\text { VHF } \\
\text { radars }\end{array}$ & $\begin{array}{c}\text { meteor } \\
\text { radar }\end{array}$ & digisonde & GPS \\
\hline São Luis & $2.6 \mathrm{~S}$ & $44 \mathrm{~W}$ & $1.5 \mathrm{~S}$ & & $\times$ & & $\times$ & $\times$ \\
Fortaleza & $3.9 \mathrm{~S}$ & $38 \mathrm{~W}$ & $5 \mathrm{~S}$ & & & & $\times$ & $\times$ \\
Cariri & $7.4 \mathrm{~S}$ & $36 \mathrm{~W}$ & $8 \mathrm{~S}$ & $\times$ & & $\times$ & & $\times$ \\
Fazenda Isabel & $15 \mathrm{~S}$ & $47 \mathrm{~W}$ & $9 \mathrm{~S}$ & $\times$ & & & & $\times$ \\
Cach. Paulista & $22.7 \mathrm{~S}$ & $45 \mathrm{~W}$ & $17 \mathrm{~S}$ & $\times$ & & $\times$ & $\times$ & $\times$ \\
\hline
\end{tabular}

\section{optical, radar, digisonde, and GPS measurement sites in Brazil employed for SpreadFEx}

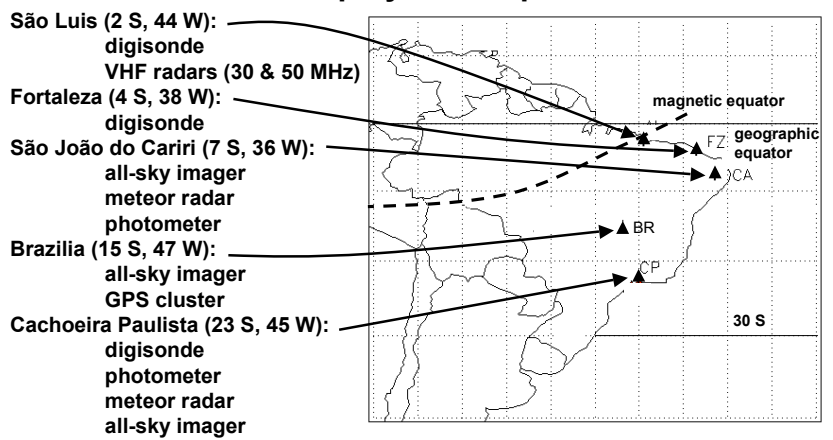

Fig. 2. Measurement sites in Brazil employed for the SpreadFEx measurement campaigns. GPS receivers were much more widely distributed, with $\sim 25$ sites available for SpreadFEx.

was located at several fixed sites, including São Luis, Fortaleza, Cariri, and Cachoeira Paulista extending from $\sim 2$ to $23^{\circ} \mathrm{S}$ geographic latitude and from $\sim 0$ to $17^{\circ} \mathrm{S}$ magnetic latitude, with GPS instrumentation more widely distributed. VHF radars at São Luis defined ESF altitudes and plasma bubble structures at the magnetic equator (de Paula and Hysell, 2004), meteor radars defined MLT winds at Cariri and Cachoeira Paulista (Batista et al., 2004; Buriti et al., 2008), digisondes defined electron densities at several dip latitudes (Batista and Abdu, 2004), airglow cameras defined both GW structures at MLT altitudes and plasma bubble structures at higher altitudes in the thermosphere at several locations south of the magnetic equator in order to assess the spatial and temporal variability of these processes (Medeiros et al.., 2004), and GPS instrumentation was employed to attempt to define the spatial and temporal variations in electron densities (Lanyi and Roth, 1988). Additional optical and GPS instrumentation was placed at several temporary sites at Fazenda Isabel north of Brasilia and several nearby sites. The instrument locations and their relation to the magnetic equator are listed in Table 1 and shown in Fig. 2.

\section{Convective activity, locations, and intensities}

Characterization of convection over Brazil during the SpreadFEx campaign was enabled by the GOES 12 satellite which performs continuous visible, IR, and water vapor measurements at 1-, 4-, and 8-km resolutions, respectively. These and related data are employed by São Sabbas et al. (2009, hereafter S09) and Vadas et al. (2009, hereafter V09) to define regions of deep convection and to quantify convective spatial and temporal scales in order to examine their potential links to sprites and GWs in additional studies in this special issue. Convection during SpreadFEx tended to be widespread and spatially variable, with occasions where deep convective cells were relatively isolated and other times and regions where there were active convective complexes. GOES 12 IR measurements of cold cloud-top temperatures and related data enabled estimates of convective plume intensities and spatial and temporal scales. Deep convection occurred primarily to the west, northwest, and southwest of our measurement sites, but significant convection also occurred over eastern Brazil and extended out over the Atlantic. Convective updraft intensities were able to be estimated from temporal variations between successive images, maximum updrafts were routinely as large as $\sim 40 \mathrm{~ms}^{-1}$, plumes penetrated to altitudes as high as $\sim 18 \mathrm{~km}$, and the larger spatial scales were able to be defined coarsely from the pixel resolution of the IR images (see S09 and V09). We also expect from recent high-resolution convective simulations, however, that GW scales are imposed in part by smallerscale updrafts within the larger-scale convection resolved by GOES 12 IR data (Lane et al., 2003; Lane and Sharman, 2006). Two examples of GOES 12 IR data showing deep convection at 20:54 UT on 24 October 2005 for two somewhat different regions, color-coded to highlight the coldest convective plumes, are shown for reference in Fig. 3. The lower image shows a number of regions of active, deep convection, five of which exhibit extensive cold temperatures, are assumed to be the largest and most mature convection, and are likely the major sources of GWs at this time in this region (S09; V09). GOES 12 imagery also indicated deep convection on 24 to 27 October extending from $\sim 10^{\circ} \mathrm{N}$ to 
$10^{\circ} \mathrm{S}$ and from $\sim 30$ to $55^{\circ} \mathrm{W}$ (upper image in Fig. 3), in closer proximity to our measurements at São Luis and Fortaleza discussed at length in several of the papers in this special issue. These times are of particular interest, as these days were one of several intervals found to coincide with considerable perturbations of the bottomside F-layer and ESF and plasma bubbles penetrating to much higher altitudes seen in radar and digisonde data obtained at São Luis and Fortaleza (see Abdu et al., 2009; Kherani et al., 2009).

\section{GW occurrence, scales, propagation directions, and amplitudes}

Our primary SpreadFEx observations of GWs in the neutral atmosphere were performed at Brasilia and Cariri, as these were the sites that had the most favorable viewing conditions and were closest $\left(\sim 10^{\circ}\right)$ to the dip equator (Taylor et al., 2009; Takahashi et al., 2009). These were also the sites at magnetic latitudes at which we anticipated possible sensitivity to the GWs thought to play a role in ESF and plasma bubble seeding through field- aligned perturbations at lower altitudes off the dip equator. Keograms of $\mathrm{OH}$ airglow brightness in the east-west plane at Brasilia and Cariri, are employed by Takahashi et al. (2009) and F08 to estimate GW propagation directions, wavelengths, and phase speeds. The large majority of the observed GWs were found to have an eastward component of propagation, suggesting that the primary sources of these GWs were likely deep convection occurring preferentially to the west of these sites, but with both northward and southward components, depending on the source location (Takahashi et al., 2009). Typical zonal wavelengths and zonal trace speeds were observed to be $\sim 20$ to $150-\mathrm{km}$ and $\sim 40 \mathrm{~ms}^{-1}$ at Brasilia and $\sim 50$ to $300-\mathrm{km}$ and $\sim 70 \mathrm{~ms}^{-1}$ at Cariri. Some caution is warranted in assuming these are horizontal wavelengths and phase speeds, however, as propagation directions also often had significant northward or southward components, causing the zonal trace speeds to over-estimate the true horizontal wavelengths and phase speeds to some degree (Taylor et al., 2009). Additionally, airglow instrumentation is unable to characterize GW scales, propagation, or the likely convective GW source locations when skies are cloudy, so we expect them to have been insensitive to convection in their immediate proximity. This was the case during the period from 24 to 27 October, when GOES 12 imagery indicated deep convection over eastern Brazil and extending northward over the Atlantic.

Amplitudes for some of the more prevalent GWs occurring at larger horizontal wavelengths in the MLT airglow layers are estimated by Vadas and Fritts (2009, hereafter VF09). Airglow intensity perturbations for GW horizontal wavelengths of $\sim 60$ to $160 \mathrm{~km}$ are found to be in the range $\sim 2$ to $7 \%$, implying fractional temperature perturbations of $\sim 1$ to $2 \%$ (assuming a Krassovsky ratio of $\eta=\left(I^{\prime} / I\right) /\left(T^{\prime} / T\right) \sim 3.3$ ). Estimates of horizontal velocity perturbations and momen-

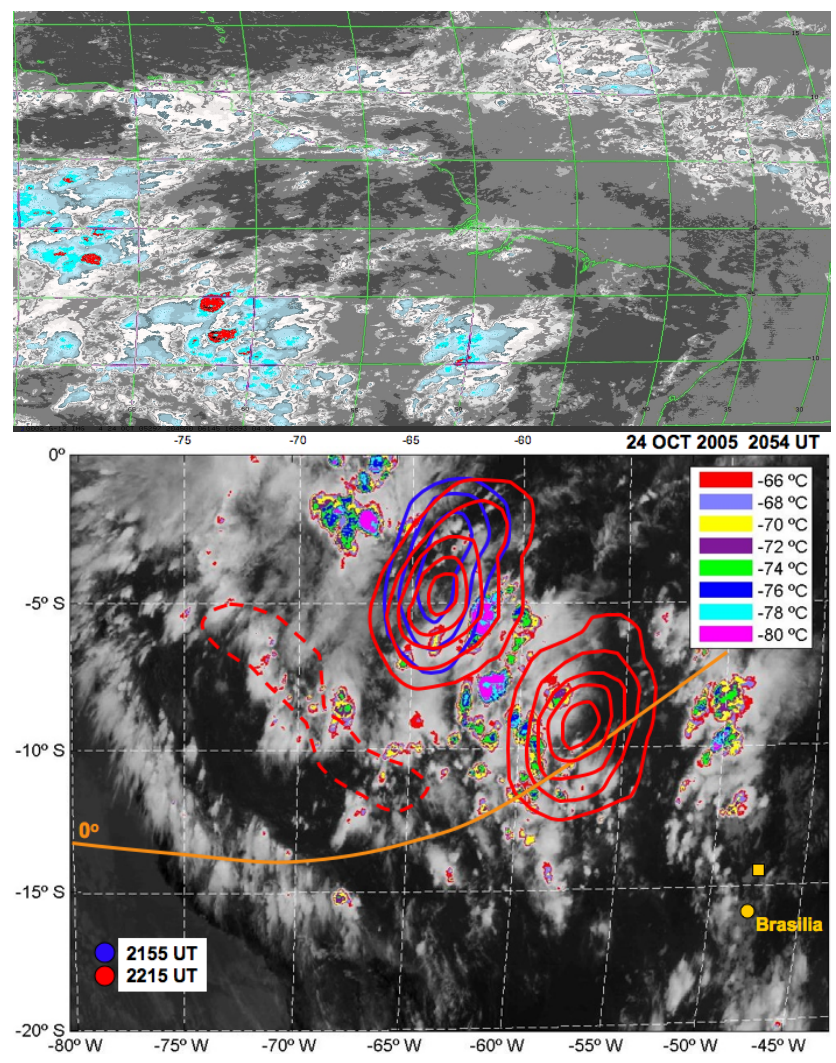

Fig. 3. GOES 12 convection observed in the IR channel at 20:54 UT on 24 October 2005. Cloud top temperatures are color coded, with solid (dashed) contours showing positive (negative) zonal GW momentum flux magnitudes at $200 \mathrm{~km}$ altitude at 21:55 and 22:15 UT (blue and red lines). The dominant GW propagation was eastward at this altitude due to primarily westward and large and variable meridional winds filtering of GWs initially propagating more isotropically. Note also that the smaller horizontal wavelength GWs have high-altitude signatures earlier and closer to the convective sources than the larger scales.

tum fluxes are also possible using the GW polarization relations and horizontal wind measurements with the INPE meteor radars to infer the intrinsic GW phase speeds (FV08; V09). These are found to be in the range $u_{h}^{\prime} \sim 3$ to $10 \mathrm{~ms}^{-1}$ and $<u_{h}^{\prime} w^{\prime}>\sim 1$ to $10 \mathrm{~m}^{2} \mathrm{~s}^{-2}$, respectively, at $\mathrm{OH}$ airglow altitudes of $\sim 87 \mathrm{~km}$. In the above, $I^{\prime}$ and $T^{\prime}$ are $\mathrm{OH}$ airglow intensity and temperature, $u_{h}^{\prime}$ and $\mathrm{w}^{\prime}$ are GW horizontal and vertical velocity perturbations, and primes and angle brackets denote perturbation quantities and spatial averages. A separate assessment of GW momentum fluxes using statistical methods is described and applied to SpreadFEx airglow measurements by Vargas et al. (2009), with similar conclusions about GW amplitudes and momentum flux magnitudes. 


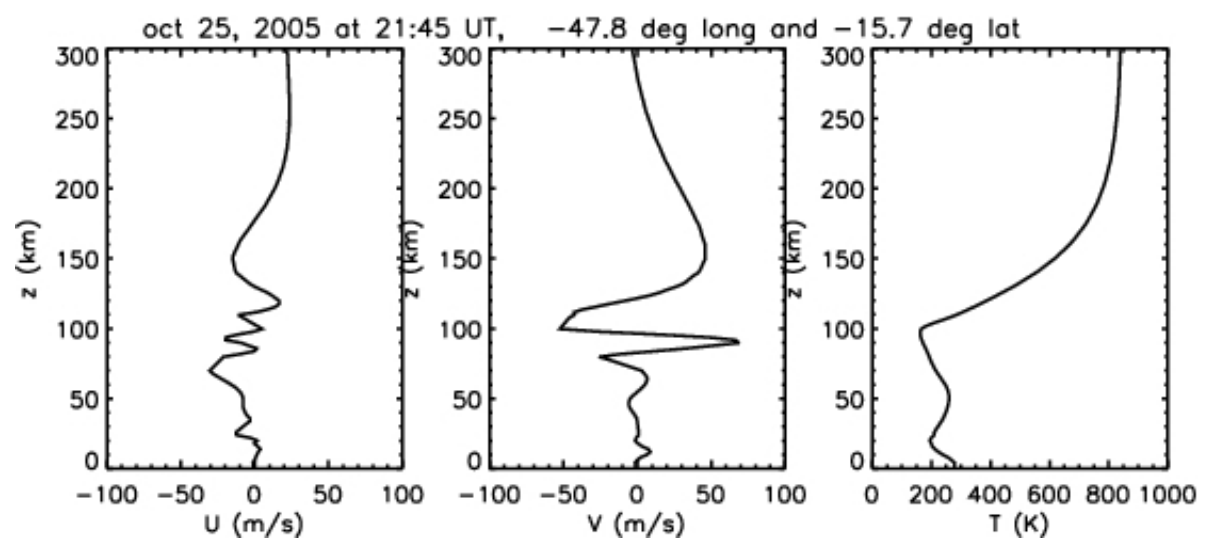

Fig. 4. Zonal (left) and meridional (center) wind and temperature (right) profiles at $\left(45^{\circ} \mathrm{W}, 10^{\circ} \mathrm{S}\right)$ used for ray tracing the GWs arising from the deep convective plumes observed in Fig. 3. The profiles were defined by balloon soundings below $30 \mathrm{~km}$, by meteor radar observations between 80 and $110 \mathrm{~km}$, and by a TIME GCM simulation initialized with the NCEP reanalysis data for this same period from 35 to $80 \mathrm{~km}$ and from 110 to $350 \mathrm{~km}$. Note the variable wind structure up to $\sim 110 \mathrm{~km}$ and the large meridional motions extending to higher altitudes, all of which have significant influences on GW propagation to high altitudes.

\section{GW propagation and dissipation theory}

Characterization of deep convection during several intervals, together with measured or anticipated winds during the same periods, is employed by V09 to perform ray tracing of GWs assumed to arise from these sources into the MLT. Portions of the initial GW spectrum for each convective source are anticipated to have reached altitudes of $200 \mathrm{~km}$ and above. Examples of the predicted zonal momentum flux distributions at two times following convective excitation (separated by $20 \mathrm{~min}$ ) are shown with the blue and red contours in Fig. 3b and exhibit the significant spatial and temporal variability expected in GW responses to transient convection and spatiallyvariable mean winds. Wind and temperature profiles employed for this study are shown in Fig. 4. While these results are highly idealized, they clearly suggest a tendency for GWs having smaller horizontal wavelengths and higher vertical group velocities (corresponding to higher intrinsic frequencies) to yield earlier responses closer to the convective source.

The GW wavelength, amplitude, and momentum flux estimates summarized above, together with reverse ray tracing to infer distances from likely convective sources by V09, are employed by VF09 to constrain representative convective GW source spectra for individual convective plumes and small convective complexes arising from our FourierLaplace description of these sources. In particular, this effort provides the most defensible link to date between observed GW scales and amplitudes and the GW spectra characterizing individual convective plumes and small convective complexes. The resulting source spectra allow F08 to anticipate likely peak GW amplitudes arising from these sources at MLT altitudes and for their extrapolation to higher altitudes for various thermospheric temperature and wind profiles. An evaluation of the refraction, filtering, and dissipation of GWs propagating from general sources in the lower atmosphere to higher altitudes demonstrates strong environmental influences on the surviving GW spatial scales and periods. The net effect is strong constraints on the horizontal and vertical wavelengths and periods that can penetrate to the bottomside F layer. Expected horizontal and vertical wavelengths arising from lower atmosphere sources are $\sim 150$ to $1000 \mathrm{~km}$ and $\sim 150$ to $500 \mathrm{~km}$ or more, respectively, with the larger horizontal scales only becoming important for stronger Dopplershifting conditions. Predicted GW amplitudes arising from these spectra are likewise substantial in the TI, with fractional temperature and horizontal velocity perturbations for the dominant motions increasing from $\sim 10 \%$ and $50 \mathrm{~ms}^{-1}$ at $\sim 200 \mathrm{~km}$ to from $\sim 20 \%$ and $100 \mathrm{~ms}^{-1}$ or greater at the highest altitudes to which these GWs penetrate under mean solar conditions (FV08). GW scales, amplitudes, and penetration altitudes are strong functions of the thermospheric temperature and wind, however, with higher temperatures and strong Doppler shifting to higher intrinsic frequencies both 1) enhancing GW filtering through refraction towards turning levels and 2) enabling the surviving GWs to achieve even higher altitudes. The net effect is that a range of thermospheric temperatures and wind environments (contributing greater or lesser Doppler shifting) enable GW penetration to altitudes at and above the bottomside F-layer with substantial perturbations to neutral and plasma fields at these altitudes (F08). The potential for large GW amplitudes at the bottomside F-layer is also suggested by SpreadFEx measurements in the ionosphere, where electron densities and inferred vertical motions exhibit large variations consistent with expectations based on GW theory (Abdu et al., 2009; Kamalabadi et al., 2009), assuming that these fluctuations are due to advection rather than chemical or electrodynamical effects. These plasma observations are summarized in greater detail below. 


\section{Plasma perturbations in the F-layer}

A major focus of our SpreadFEx measurement campaign and our subsequent data analyses was the characterization of perturbations to plasma quantities from below the bottomside F-layer to much higher altitudes. This included 1) identification of the amplitudes, spatial and temporal scales, motions, and morphologies of electron densities and gradients at all altitudes where SpreadFEx measurements provided sensitivity, 2) determination of the sources of the various perturbations (i.e., either a manifestation of neutral dynamics inducing plasma signatures or a response to purely plasma processes), and 3) identification of potential links and/or correlations between apparently neutral and plasma processes. Plasma perturbations ranged from structures at the bottomside F-layer having small horizontal scales and limited vertical extent to plasma bubbles extending over hundreds of $\mathrm{km}$ in altitude and yielding large density perturbations seen with our various SpreadFEx instrumentation.

SpreadFEx measurements in the ionosphere employed ground-based VHF radars, $6300 \AA$ airglow imagers, GPS receivers, and digisondes, at various sites in Brazil and the GUVI instrument aboard the TIMED satellite. The higher and deeper perturbations seen at the higher altitudes are considered unambiguous indications of plasma bubbles initiated via initial plasma instabilities and RTI at the bottomside Flayer and extending to the topside. Electron density perturbations seen before plasma bubbles are expected to occur, however, are more likely to be plasma signatures of neutral dynamics arising from tidal and GW perturbations of the ionosphere. Only at the bottomside F-layer do we expect to see plasma structures that may have an ambiguous interpretation and include perturbations due to neutral and plasma dynamics together that may be causally related.

Plasma bubbles extending into the topside F-layer are characterized in this special issue using a $30 \mathrm{MHz}$ VHF radar (beamwidth $\sim 16^{\circ}$ ), $6300 \AA$ Airglow imagers, GPS receivers, and the GUVI instrument by Abdu et al. (2009) and Kamalabadi et al. (2009), respectively. Range-time intensity (RTI) plots of VHF radar backscatter power are shown in Fig. 5 for two nights during the second SpreadFEx measurement interval, 24/25 and 25/26 October 2005, that are of particular interest in our analyses. These show plasma bubbles apparently initiated near $250 \mathrm{~km}$ and extending to over $600 \mathrm{~km}$ with a temporal spacing between 1 and $2 \mathrm{~h}$ (see Abdu et al., 2009, for further discussion). Significantly, these responses at the bottomside F-layer coincide with the presence of deep convection $\sim 800 \mathrm{~km}$ south and northwest of São Luis and Fortaleza at this time (see Fig. 3a). There is also significant fine structure in these images suggestive of plasma dynamics on shorter time scales, but the broad radar beam employed for these images precludes definition of features having spatial scales less than the beam width. Additionally, these images provide no information on the spacing of the larger plumes
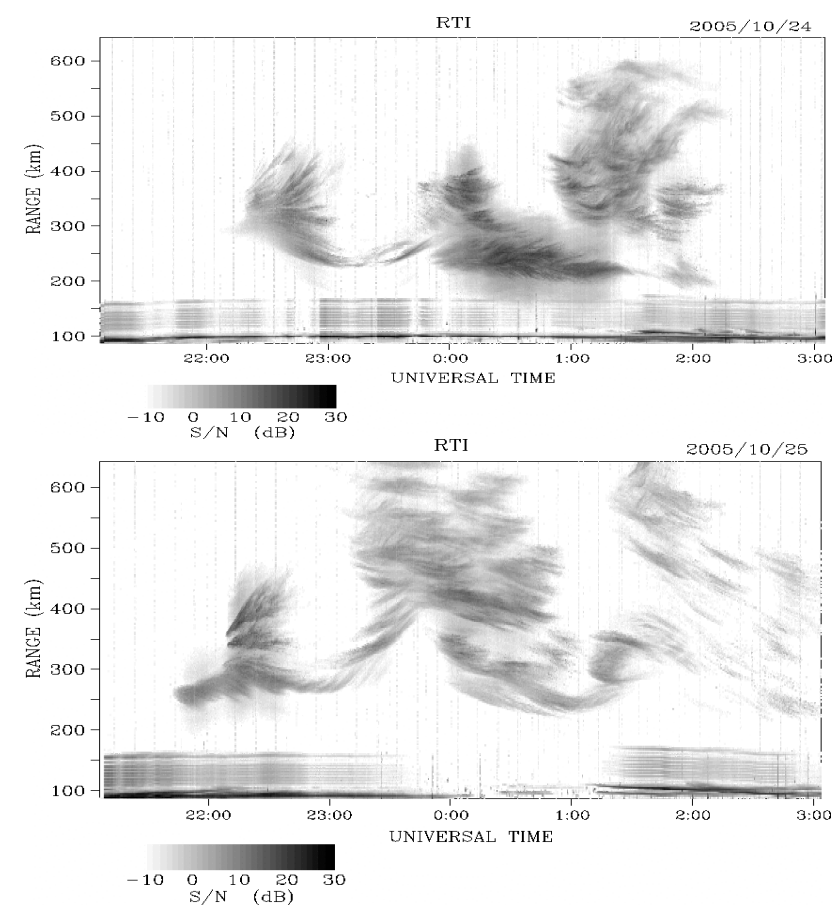

Fig. 5. Spread F and plasma bubbles observed in the zenith on $24 / 25$ (top) and 25/26 October 2005 (bottom) by the VHF radar at São Luis during the SpreadFEx measurement campaign. The plume occurrence on both days follows closely the uplifted bottomside Flayer seen in Fig. 8 below and exhibits a similar periodicity.

without knowledge of the plasma drifts at these altitudes, which themselves vary spatially and temporally.

Information on plasma bubble spacing is obtained, however, by employing observations with the $6300 \AA$ airglow imagers located at Brasilia and Cariri during SpreadFEx. An example of these data is shown in Fig. 6 and reveals typical bubble spacings of $\sim 50$ to $300 \mathrm{~km}$ or larger. Simultaneous MLT and $6300 \AA$ airglow measurements also permit correlations between apparent neutral atmosphere and plasma structures. A correlation of the spatial scales of GWs in the MLT and plasma bubbles at higher altitudes is performed by Takahashi et al. (2009) and provides suggestive and surprising evidence of potential direct $\mathrm{GW}$ influences extending from the MLT to the bottomside F-layer.

A separate interferometric analysis of the São Luis VHF radar data by Rodrigues et al. (2008) also provides sensitivity to much smaller spatial scales than is possible without using this method. Their results suggest characteristic instability scales of $\sim 30 \mathrm{~km}$ which cannot be due to GWs at these altitudes and suggest instead a plasma collisional shear instability as the source of perturbations at these spatial scales. These results are unable to assess the potential for largerscale perturbations that might exhibit GW influences, however, and are thus unable to address the seeding dynamics of the larger-scale plasma bubbles that penetrate most easily to the highest altitudes. 


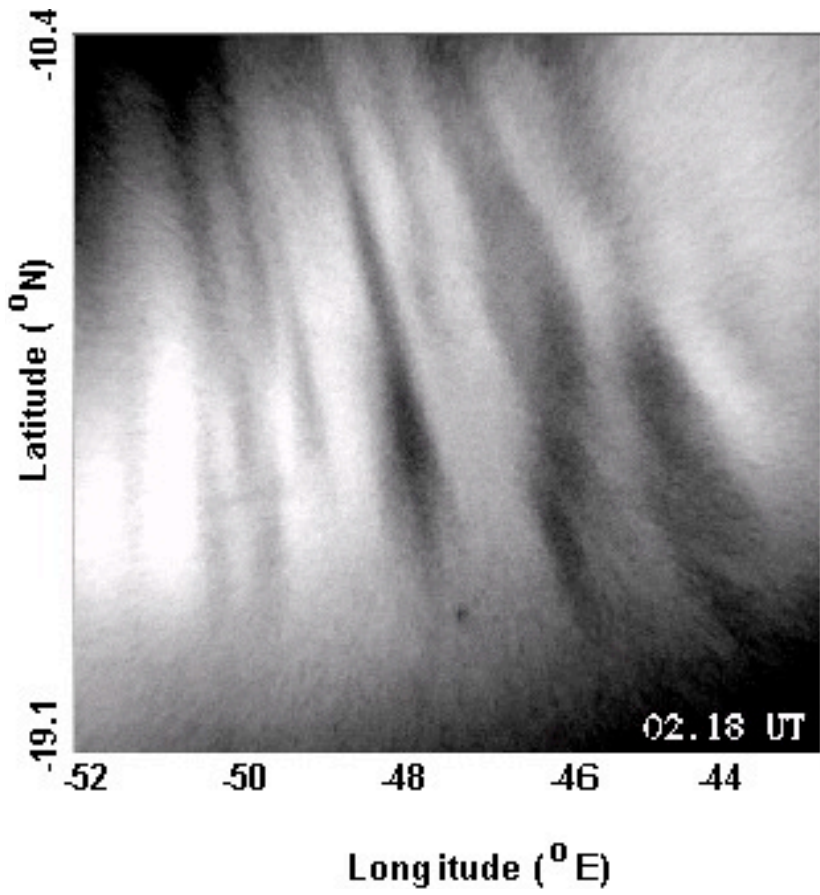

Fig. 6. $6300 \AA$ airglow image obtained at Cariri on 2 October 2005 . Brightness represents integrated emissions along the line of sight and intensities have been mapped to corresponding latitudes and longitudes assuming a peak emission altitude of $350 \mathrm{~km}$. Dark bands indicate depletions in emission intensity within plasma bubbles, bubbles are aligned along the magnetic field lines, and bubbles are spaced in the normal plane by $\sim 50$ to $300 \mathrm{~km}$ or more.

GPS measurements likewise shed light on the nature of perturbations near the peak of the F-layer. Examples of the perturbations in the temporal derivative of TEC seen in these data collected at Fortaleza on the evening of 24 October 2005 are shown for reference in Fig. 7. While it is challenging to infer specific scales unambiguously because these data mix variations due to phase motions of the TEC perturbations and motions of the piercing points associated with the various GPS satellites, we nevertheless see periods ranging from $\sim 20$ to $60 \mathrm{~min}$ prior to $\sim 21: 20 \mathrm{UT}$, which is considered to be onset time for RTI and plasma bubbles at this location (Swartz and Woodman, 1998). This means that these perturbations cannot be associated with plasma bubbles and that they are almost certainly due to perturbations of the electron densities by large-amplitude GWs having large vertical scales. These observations appear to validate predictions by FV08 in this issue that GWs from sources in the lower atmosphere having just these observed periods will reach the peak of the F-layer under mean solar and nominal Doppler shifting conditions. If so, they clearly also have the potential to impose significant perturbations at the bottomside F-layer that will be further explored elsewhere in the special issue.

Observations of plasma perturbations at and below the bottomside F-layer were also possible during SpreadFEx using

\section{GPS d(TEC)/dt fluctuations over Forteleza ( $350 \mathrm{~km})$}

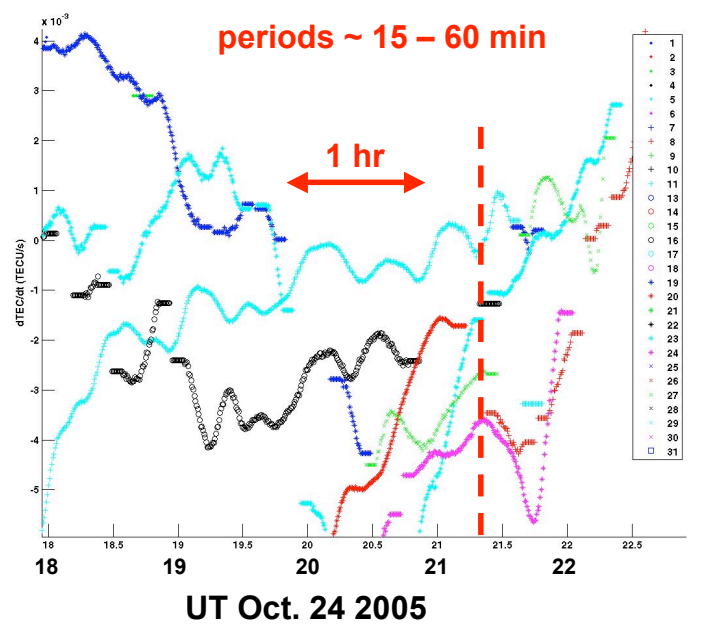

Fig. 7. Time series of d(TEC)/dt for eight GPS satellite traverses observed from Fortaleza during the evening of 24 October 2005. Note that most oscillations have apparent periods of $\sim 20 \mathrm{~min}$ to $1 \mathrm{~h}$ and that oscillations are apparent well before spread $\mathrm{F}$ and plasma bubble onset, shown approximately by the dashed red line.

the INPE digisondes at São Luis and Fortaleza and on a more limited basis with the GUVI instrument aboard TIMED. Digisonde data discussed in detail by Abdu et al. (2009) and Takahashi et al. (2009) in this issue exhibit large electron density perturbations over altitudes extending throughout the bottomside F-layer to the F-layer peak. Examples of digisonde measurements at São Luis from 24 to 27 October 2005 are shown in the upper panel of Fig. 8 and suggest large perturbation amplitudes and vertical velocities, with peak-topeak vertical excursions approaching $\sim 100 \mathrm{~km}$. These perturbations also exhibit clear downward phase progressions on occasion and thus suggest GWs as the source of these perturbations (F08). The digisonde data are somewhat restricted in temporal resolution, however, with 10- min resolution and only a 20-min Nyquist period. This results in potential underestimates of the amplitudes of the higher-frequency motions that are also believed to attain these altitudes, and it may account for some of the disparity between electron density perturbation estimates by the INPE digisondes, $\sim 10$ to $40 \%$, and the GUVI data discussed below (attributed, in part, by F08 to varying $H_{e}$ with altitude, see below). We must also be careful, however, to not ascribe large electron density perturbations to GWs that may instead be due to geomagnetic influences. But the $K_{p}$ index (lower panel in Fig. 8), as well as Dst and the ACE/MAG magnetic fields, were weak to moderate at these times and suggest no significant magnetic influences (F08). GUVI measurements of $1356 \AA$ emissions provide a daily global view of equatorial Flayer plasma structures (Fig. 9, left). An example that reveals depletions in these emissions corresponding to the plasma 

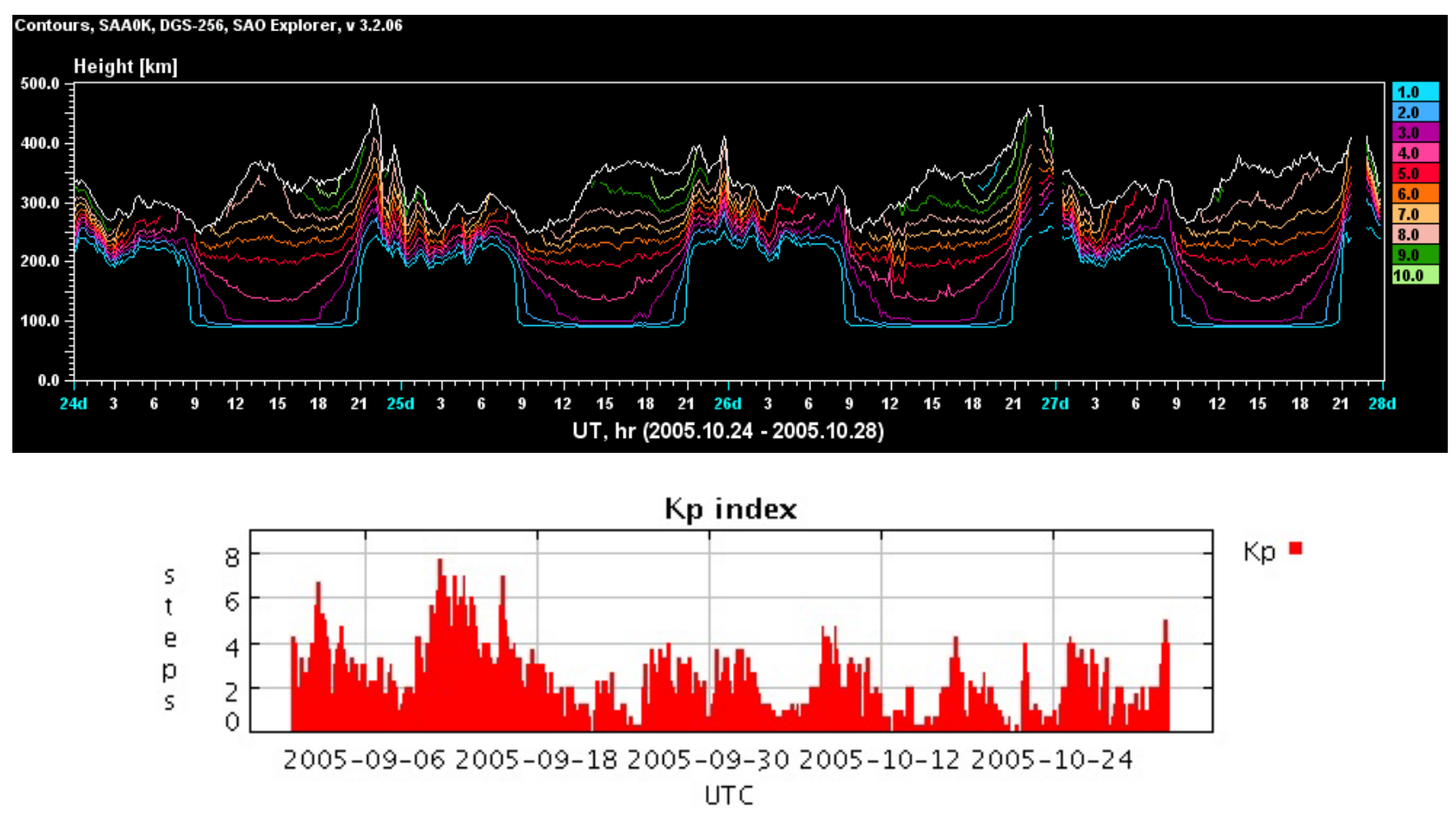

Fig. 8. Digisonde measurements at São Luis for 24 to 27 October 2005 (upper panel) showing significant perurbations of the bottomside F-layer and above ( $\sim 200$ to $400 \mathrm{~km}$ ), especially on the first two nights. $K_{p}$ index (lower panel) during September and October 2005. Corresponding tabular data yield mean values of $1,3.5,2.5$, and $<2$ for 24 to 27 October, respectively, averaged in UT, suggesting only weak to moderate magnetic activity.

bubbles is shown in the right panel of Fig. 9. These orbits have a component of the satellite motion normal to the magnetic field lines and thus permitted tomographic inversions of these data by Kamalabadi et al. (2009) in this issue, assuming that electron density perturbations were aligned along these field lines. These GUVI tomographic inversions indicate fractional electron density perturbations at the bottomside (and topside) F-layer that are substantially larger than those inferred from digisonde data at the bottomside F-layer (due to smaller $H_{e}$ at the bottomside F-layer, F08). These perturbations also extend to much lower altitudes than can be inferred from the digisonde data and have relatively large spatial scales, $\sim 200$ to $500 \mathrm{~km}$ (see Kamalabadi et al., 2009; F08). These spatial scales and the downward phase motions noted in the digisonde data (Abdu et al., 2009) suggest possible GW influences on the plasma at these altitudes, but downward mapping of plasma bubbles from higher altitudes at the dip equator also cannot be discounted as an explanation.

\section{GW and tidal perturbations at the bottomside F-layer}

As noted above, VF09 employ the reverse ray tracing results of V09 to infer "best fit" GW source spectra for rep- resentative individual convective plumes and small convective complexes including three closely spaced plumes. The theoretical study by FV08 uses the same techniques to identify the GW horizontal and vertical wavelengths and periods anticipated to penetrate to the highest altitudes for various thermospheric temperatures and winds, independent of GW sources at lower altitudes. Together, these studies constrain theoretically the GW amplitudes and scales that can influence bottomside F-layer plasma dynamics from sources in the lower atmosphere. FV08 anticipate horizontal and vertical wavelengths arising from lower atmosphere sources to be $\sim 150$ to $1000 \mathrm{~km}$ and $\sim 150$ to $500 \mathrm{~km}$ or more at the bottomside F-layer, respectively, with the larger horizontal scales only becoming important for stronger Doppler-shifting conditions. Of these, only the smaller wavelengths, $\sim 150$ to $500 \mathrm{~km}$ horizontally and $\sim 150$ to $300 \mathrm{~km}$ vertically, are expected to propagate efficiently to the highest altitudes with the largest remaining amplitudes.

The source spectra inferred by VF09 are used by F08 to estimate the distributions of maximum GW horizontal velocity perturbations as functions of GW horizontal and vertical wavelengths occurring at $80 \mathrm{~km}$ at a range and time determined by the GW frequency in an atmosphere at rest. Maximum GW amplitudes are estimated to be $\sim 1$ to $2 \mathrm{~ms}^{-1}$ 

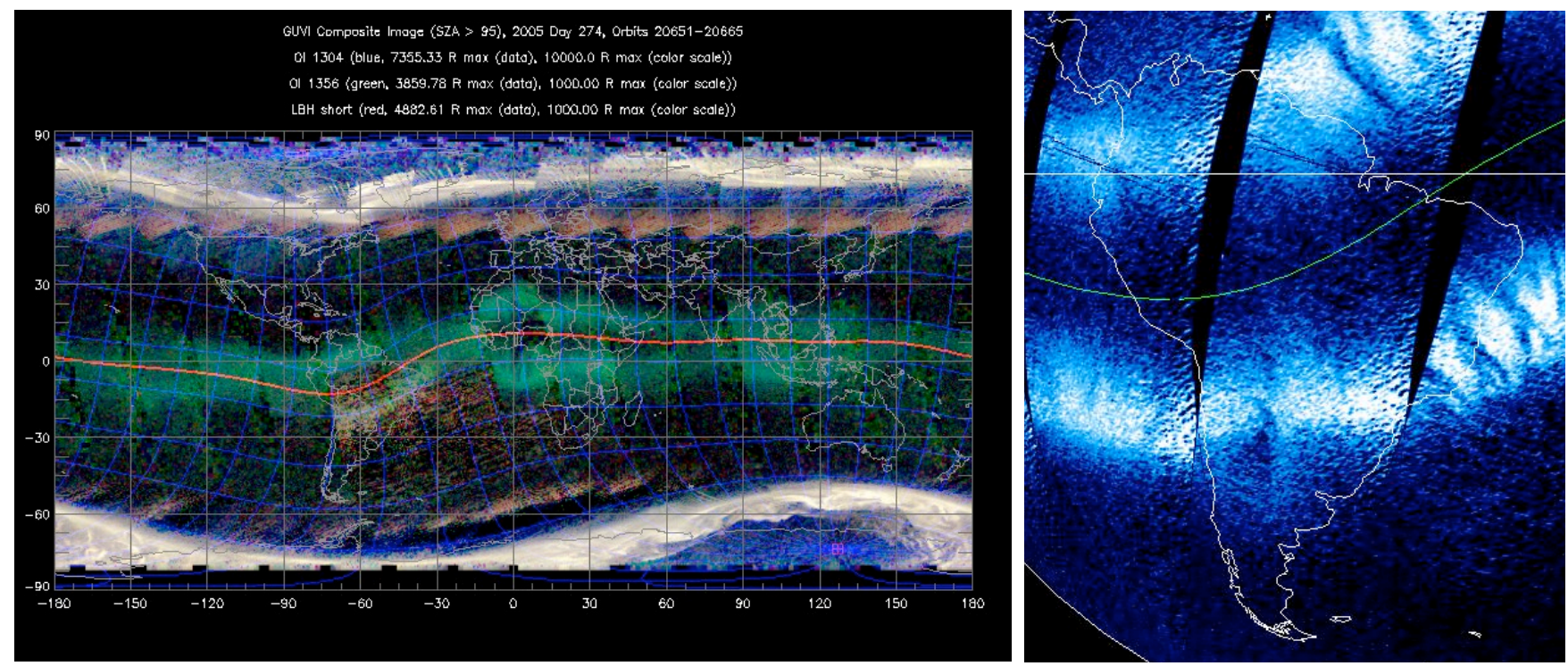

Fig. 9. Global TIMED/GUVI $1356 \AA ̊$ emissions (green) on successive orbits (left) on day 274 (1 October) 2005 during the first SpreadFEx measurement campaign and a closer view (right) over South America exhibiting plasma depletions in $1356 \AA$ emissions.

at vertical and horizontal wavelengths of $150 \mathrm{~km}$ and $\sim 200$ to $400 \mathrm{~km}$, respectively, for a single plume. Amplitudes $\sim 2$ times larger are expected in response to a small convective complex. Expected maximum amplitudes for both sources are also $\sim 2$ times smaller at vertical wavelengths of $\sim 200 \mathrm{~km}$. As a result, F08 employ a GW horizontal velocity perturbation $1 \mathrm{~ms}^{-1}$ as a conservative upper limit for the purpose of estimating amplitudes at higher altitudes.

The implications of these $\mathrm{GW}$ amplitudes at $80 \mathrm{~km}$ for perturbations at the bottomside F-layer are explored in detail by F08. They also consider superposed GW and tidal motions because it is believed that tidal winds largely account for filtering of the spectrum of GWs propagating from lower altitudes and for the eastward winds following sunset that allow for the neutral-plasma differential velocity contributing to plasma instability growth rates (FV08; F09; Kudeki et al., 2007). F08 infer GW velocity, neutral and electron density, and electron density gradient perturbations that vary as

$u_{h}^{\prime}=-\left(m / k_{h}\right) w^{\prime} \sim\left(m / k_{h}\right)\left(g \omega / N^{2}\right) \rho^{\prime} / \rho=\hat{a}(g / N) \rho^{\prime} / \rho$,

$\left(\rho_{e}^{\prime} / \rho_{e}\right) /\left(\rho^{\prime} / \rho\right) \sim-(2-\gamma) / 2(\gamma-1)-\gamma H(\gamma-1) H_{e}$,

and

$$
\left(\partial \rho_{e}^{\prime} / \partial z\right) /\left(\partial \rho_{e} / \partial z\right)=\left(H_{e} / \rho_{e}\right) \partial \rho_{e}^{\prime} / \partial z \sim\left(1+i m H_{e}\right)\left(\rho_{e}^{\prime} / \rho_{e}\right),
$$

where $k_{h}=2 \pi / \lambda_{h}$ and $m=2 \pi / \lambda_{z}$ are the horizontal and vertical GW wavenumbers, $\lambda_{h}$ and $\lambda_{z}$ are the horizontal and vertical GW wavelengths, $g$ is gravity, $\omega$ is the GW intrinsic frequency, $N$ is the buoyancy frequency, $H$ and $H_{e}$ are the neutral and electron density scale heights, $\rho^{\prime} / \rho$ and $\rho_{e}^{\prime} / \rho_{e}$ are the fractional neutral and electron density perturbations, $\gamma=c_{p} / c_{v}=1.4$ and $\beta \sim\left(1-\omega^{2} / N^{2}\right)^{1 / 2} \sim 0.5$ to 1 represents the degree to which the GWs depart from hydrostatic. For mean solar conditions and a GW horizontal velocity perturbation of $u h^{\prime} \sim 50 \mathrm{~ms}^{-1}$, these yield

$\rho^{\prime} / \rho \sim 5$ to $10 \%$,

$\rho_{e}^{\prime} / \rho_{e} \sim 20$ to $40 \%$,

and

$\left(\partial \rho_{e}^{\prime} / \partial z\right) /\left(\partial \rho_{e} / \partial z\right) \sim 2$ to $5 \rho_{e}^{\prime} / \rho_{e}$,

where F08 assumed that the GW propagates vertically with $\mathrm{m}$ real, GW dissipation is weak, $H_{e} \geq 1 / \mathrm{m}, \lambda_{z} \sim 200 \mathrm{~km}$, $H \sim 30 \mathrm{~km}$, and $H_{e} \sim 30$ to $100 \mathrm{~km}$. These electron density perturbations and their gradients are twice as large for $u_{h}^{\prime} \sim 100 \mathrm{~ms}^{-1}$, which appears to be very plausible at these altitudes. They also are in very good agreement with the electron density perturbations (and gradients) that are inferred from the SpreadFEx digisonde and GUVI data summarized above, and which appear to validate the GW amplitudes and spatial scales at these altitudes predicted to arise from convective sources. We note, however, that these estimates of electron densities and gradients assume only neutral dynamical influences and neglect possible chemical and electrodynamical effects that may in fact also be significant.

F08, F09, and Meriwether et al. (2008) call attention to the potential role of tidal motions in preconditioning the bottomside F-layer for plasma instabilities. Based on Thermosphere Ionosphere Mesosphere Electrodynamics (TIME) general circulation model (GCM) simulations, it appears that tidal motions may contribute potentially significant winds of $\sim 100$ to $200 \mathrm{~ms}^{-1}$ at the bottomside F-layer and above, with eastward winds (that vary day to day) increasing about the 
time of plasma bubble seeding and contributing to 1) refraction and filtering of GWs entering the bottomside F-layer from below, 2) observed predominantly eastward plasma drifts, 3) a neutral wind-plasma drift velocity differential (and shear), 4) temporal variability of plasma drifts that may account for the retrograde drifts observed on occasion at later times, and 5) impacts on thermospheric temperature and plasma density profiles at the bottomside F-layer that may themselves impact plasma instability growth rates. F08 also describe several specific scenarios in which GW and/or tidal structures can combine or align to enhance the field-lineintegrated parameters that enhance plasma instability growth rates advocated by previous authors. Their primary conclusions are that GW and tidal superpositions can collectively enhance several or all of the parameters impacting plasma instability growth rates, depending on the nature of the GW motions.

\section{GW and tidal influences on plasma instability and bubble formation}

We summarized above the SpreadFEx studies aimed at defining and quantifying GW convective sources at lower altitudes, their apparent links and propagation to the MLT and the bottomside F-layer, and the observational and theoretical evidence for specific GW amplitudes, scales, and orientations at the bottomside F-layer. Together, these efforts make a compelling case that GWs arising from deep convection can reach the bottomside F-layer with amplitudes and scales that we might expect to impact plasma instability growth rates and set the stage for specific assessments of the impacts of these perturbations on plasma instability growth rates. Additional papers in this special issue by Abdu et al. (2009) and Kherani et al. (2009) perform these assessments through linear theory and nonlinear numerical simulations.

Abdu et al. (2009) employ SpreadFEx measurements at São Luis and Fortaleza (at dip angles of $-3^{\circ}$ and $-12^{\circ}$, respectively), observational assessments of $\mathrm{GW}$ amplitudes and scales at the bottomside F-layer, and linear theoretical calculations of RTI, to investigate the role of GWs in the instability initiation at the bottomside F-layer. Several days representative of differing precursor conditions with varying pre-reversal vertical drifts, bottomside F-layer density gradients, and GW density and wind perturbations are considered. The conclusions of this study include the following: 1) apparent GW structures at the bottomside F-layer appear to be consistent with observations and theory suggesting that these GWs arise from deep tropical convection, 2) there is considerable day-to-day variability in the precursor conditions leading to initial plasma instabilities and of the GW contributions to these conditions, 3) GW density perturbations are not required to initiate instability leading to topside plasma bubbles when vertical drifts exceed $\sim 30 \mathrm{~ms}^{-1}$, but they appear to be a necessary condition when vertical drifts are $\sim 20 \mathrm{~ms}^{-1}$ or less, 4) GW wind perturbations can lead to significant enhancements of polarization electric fields contributing to plasma instability, depending on the F-layer vertical drift, height, and density gradient, 5) GWs likely play a significant role in plasma instability and plasma bubble initiation, especially when F-layer conditions themselves are marginal for plasma instabilities, and 6) the interplay between F-layer conditions and day-to-day variability in GW perturbations at the bottomside F-layer suggest that GWs may be an important cause of the day-to-day variability of ESF and plasma bubble occurrence.

Kherani et al. (2009) perform a similar assessment of plasma instability dynamics to that by Abdu et al. (2009), except that they employ a nonlinear numerical model of the influences of bottomside F-layer structure and GW perturbations on collisional-interchange instability and nonlinear plasma bubble growth into the topside F-layer. Like Abdu et al. (2009), they employ specific guidance from direct measurements of bottomside F-layer structure and apparent GW perturbations of the density and wind fields at these altitudes. They also employ a linear model of GW vertical propagation from an assumed convective source altitude to directly assess GW perturbation amplitudes at the bottomside F-layer. Their primary conclusions closely parallel those of Abdu et al. (2009) and include: 1) GW wind perturbations can play a key role in plasma bubble seeding, but they are neither necessary nor certain to do so, 2) large GW perturbations can result in deep plasma bubbles when ionospheric conditions are not conducive by themselves, 3 ) weaker GW perturbations can trigger significant bubble events when ionospheric conditions are more favorable, and 4) weak GW perturbations in less favorable environments cannot, by themselves, lead to strong plasma bubble responses.

Summarizing, the linear and nonlinear assessments of plasma instability dynamics at the bottomside F-layer by Abdu et al. (2009) and Kherani et al. (2009) appear to be in agreement with each other, with the observational data with which each set of growth rate predictions are compared, and with the expectations of potential impacts based on the assessment of GW perturbations at the bottomside F-layer by F08. Together, these studies suggest an important, but not exclusive, role for GW perturbations at the bottomside F-layer in 1) modulating plasma instability processes, 2) contributing to initial plasma instability, RTI, plasma bubble initiation, and day-to-day variability in plasma bubble occurrence, and 3 ) enhancing the potential for plasma instability and plasma bubble initiation when bottomside F-layer conditions are insufficient themselves for significant instability development.

\section{Observational and modeling studies of mesospheric bores}

While the major foci of SpreadFEx measurements and analyses were on GW coupling from convective sources to, and 
possible influences at, the bottomside F-layer, the airglow imager and meteor radar data collected during the campaign at Cariri, and in one case supplemented by a coincident vertical temperature profile near Cariri obtained by the SABER instrument aboard the TIMED satellite, also enabled observations of several mesospheric bore events and a detailed analysis of one of these. This study by Fechine et al. (2009) provides a detailed assessment of the ducting environment, the responses in two airglow layers, and the bore structure, its apparent altitude, and its evolution in time. They conclude that the wind profile played a major role in defining the duct at which the observed bore propagated, causing this to be the first clear case of Doppler ducting of a mesospheric bore event in the literature. The key to this ducting environment was a strong and variable wind profile with altitude, despite significant variability also exhibited by the SABER temperature profile.

Motivated by an expectation that MLT wind and temperature profiles contribute to complex ducting environments, and the first documentation by Fechine et al. (2009) of a mesospheric bore supported by a Doppler duct, Laughman et al. (2009) explore thermal and Doppler ducting conditions enabling bore formation from an initially sinusoidal, long-wave perturbation centered at the ducting level. For both a thermal and a Doppler duct, the result is an undular bore structure in temperature and velocity having successive peaks emerging with time. The bore oscillations in temperature and velocity also follow a significant reduction in both the temperature and horizontal wind preceding the bore response. Laughman et al. (2009) also explore the importance of boundary conditions in properly describing bore responses and the simultaneous occurrence of adjacent thermal and Doppler ducts, as might be expected to occur based on the inertia-gravity wave and tidal structures that dominate the MLT variance fields. In this case, an initial bore response at one duct can "tunnel" to the adjacent duct, leading to a nonlinear response at both ducts at later times.

\section{Summary and conclusions}

This overview of the Spread F Experiment (SpreadFEx) has reviewed the scientific motivation for our measurement and analysis program, described the components of our measurement campaign in Brazil, and introduced and summarized the various analyses presented in this special issue. The key results of our collective efforts include the following:

1. deep convection appears to be a significant and viable source of GWs penetrating into the MLT and to the bottomside F-layer, depending on GW scales, frequencies, propagation directions, and large-scale winds;

2. GWs spanning a wide range of scales and frequencies reach the MLT, but only GWs having large scales and high frequencies can reach the highest altitudes;
3. GWs arising from convection are strongly influenced by lower atmospheric, MLT, and thermospheric winds. These dictate which GW frequencies, scales, and propagation directions penetrate to the bottomside F-layer and above;

4. Digisonde, GUVI, and GPS electron density measurements collectively suggest GWs exhibiting downward phase motions (upward propagation), observed periods of $\sim 20 \mathrm{~min}$ to $2 \mathrm{~h}$, zonal wavelengths of $\sim 200$ to $500 \mathrm{~km}$, and large electron density (and gradient) perturbations extending from $\sim 100 \mathrm{~km}$ to the bottomside F-layer, with implied neutral density and wind perturbations of $\sim 2$ to $20 \%$ and $\sim 10$ to $100 \mathrm{~ms}^{-1}$;

5. VHF radar and digisonde data suggest a connection between rising motions, decreasing electron densities, increasing electron density gradients, and plasma bubble initiation;

6. tidal winds at the bottomside F-layer appear to play a key role in enabling spread $F$ seeding, given the transition from westward to eastward neutral motions in the early evening and the influences of these winds on GW propagation;

7. GWs having sufficiently large perturbation amplitudes likely contribute to plasma instabilities at the bottomside F-layer, particularly when bottomside F-layer conditions are not themselves conducive to instability; GWs of smaller amplitudes may also play a role in modulating plasma instabilities and determining instability scales when the bottomside F-layer is sufficiently unstable itelf; and

8. GWs exhibit a variety of other MLT dynamics, including GW-mean flow and tidal interactions and bore excitation indicative of strong nonlinear responses.

Acknowledgements. The SpreadFEx field program and data analysis were supported by NASA under contracts NNH04CC67C and NAS5-02036. Related modeling and theoretical activities were supported by NSF grants ATM-0314060, ATM-0436703, and ATM0537311 and AFOSR contract FA9550-06-C-0129. We also thank M. R. Hausman and L. J. Nickisch for their assistance in analyzing GPS data from Fortaleza and V. T. Rampinelli, E. Bataglin, J. Sempere, N. D. Cândido, and the São João d'Aliança's House of Representatives and Mayor's House for local support during the campaign. CPTEC-INPE provided assistance with the GOES 12 data analysis. Some of the authors also had partial support from Conselho Nacional de Desenvolvimento Cietifico e Tecnologico CNPq (Abdu, Sobral, de Paula, I. Batista, Takahashi, and Gobbi).

Topical Editor U.-P. Hoppe thanks J. Makela and another anonymous referee for their help in evaluating this paper. 


\section{References}

Alam Kherani, E., Abdu, M. A., de Paula, E. R., Fritts, D. C., Sobral, J. H. A., and de Meneses Jr., F. C.: The impact of gravity waves rising from convection in the lower atmosphere on the generation and nonlinear evolution of equatorial bubble, Ann. Geophys., 27, 1657-1668, 2009, http://www.ann-geophys.net/27/1657/2009/.

Abdu, M. A.: Outstanding problems in the equatrial ionospherethermosphere system relevant to spread F, J. Atmos. Solar Terr. Phys., 63, 869-884, 2001.

Abdu, M., Kherani, E. A., Batista, I. S., de Paula, E. R., and Fritts, D. C.: Gravity wave influences on plasma instability growth rates based on observations during the Spread F Experiment (SpreadFEx), Ann. Geophys., in press, 2009.

Abdu, M. A., Batista, I. S., and Sobral, J. H. A.: A new aspect of magnetic control of equatorial spread F, J. Geophys. Res., 97, 14897-14904, 1992.

Abdu, M. A., Batista, I. S., Takahashi, H., MacDougall, J., Sobral, J. H., Medeiros, A. F., and Trivedi, N. B.: Magnetospheric disturbance induced equatorial plasma bubble development and dynamics: A case study in Brazilian sector, J. Geophys. Res., 108(A12), 1449, doi:10.1029/2002JA009721, 2003.

Aggson, T. L., Maynard, N. C., Hanson, W. B., and Saba Jack, L.: Electric field observations of equatorial bubbles, J. Geophys. Res., 97, 2997-3009, 1992.

Anderson, D. N., Richmond, A. D., Balsley, B. B., Roble, R. G., Biondi, M. A., and Sipler, D. P.: In situ generation of gravity waves as a possible seeding mechanism for equatorial spread-F, Geophys. Res. Lett., 9, 789-792, 1982:.

Batista, I. S. and Abdu, M. A.: Ionospheric variability at Brazilian low and equatorial latitudes: comparison between observations and IRI model, Adv. Space Res., 34, 1894-1900, 2004.

Batista, P. P., Clemesha, B. R., Tokumoto, A. S., and Lima, L. M.: Structure of the mean winds and tides in the meteor region over Cachoeira Paulista, Brazil $\left(22.7^{\circ} \mathrm{S}, 45^{\circ} \mathrm{W}\right)$ and its comparison with models, J. Atmos. Solar-Terr. Phys., 66(6-9), 623-636, 2004.

Buriti, R. A., Hocking, W. K., Batista, P. P., Medeiros, A. F., and Clemesha, B. R.: Observations of equatorial mesospheric winds over Cariri $\left(7.4^{\circ} \mathrm{S}\right)$ by a meteor radar and comparison with existing models, Ann. Geophys., 26, 485-497, 2008,

http://www.ann-geophys.net/26/485/2008/.

de Paula, E. R. and Hysell, D. L.: The São Luis $30 \mathrm{MHz}$ coherent scatter ionospheric radar: system description and initial results, Radio Sci., 39, RS1014, doi:10.1029/2003RS002914, 2004.

Djuth, F. T., Sulzer, M. P., Elder, J. H., and Wickwar, V. B.: Highresolution studies of atmosphere-ionosphere coupling at Arecibo Observatory, Puerto Rico, Radio Sci., 32, 2321-2344, 1997.

Djuth, F. T., Sulzer, M. P., Gonzales, S. A., Mathews, J. D., Elder, J. H., and Walterscheid, R. L.: A continuum of gravity waves in the Arecibo thermosphere?, Geophys. Res. Lett., 31, L16801, doi:10.1029/2003GL019376, 2004.

Earle, G., Musumba, A. M., and Vadas, S. L.: Satellitebased measurements of gravity wave- induced midlatitude plasma density perturbations, J. Geophys. Res., 113, A3303, doi:10.1029/2007JA012766, 2008.

Fechine, J., Wrasse, C. M., Takahashi, H., Medeiros, A. F., Batista, P. P., Clemesha, B. R., Lima, L. M., Fritts, D., Laughman, B., Taylor, M. J., Pautet, P. D., Mlynczak, M. G., and Russell, J. M.:
First observation of an undular mesospheric bore in a Doppler duct, Ann. Geophys., 27, 1399-1406, 2009,

http://www.ann-geophys.net/27/1399/2009/.

Fejer, B. G., Scherliess, L., and de Paula, E. R.: Effects of the vertical plasma drift velocity on the generation and evolution of equatorial spread F, J. Geophys. Res., 104, 19859-19869, 1999.

Fritts, D. C. and Alexander, M. J.: Gravity dynamics and effects in the middle atmosphere, Rev. Geophys., 41, 1003, doi:10.1029/2001RG000106, 2003.

Fritts, D. C., Abdu, M. A., Batista, B. R., Batista, I. S., Batista, P. P., Buriti, R., Clemesha, B. R., Dautermann, T., de Paula, E., Fechine, B. J., Fejer, B., Gobbi, D., Haase, J., Kamalabadi, F., Laughman, B., Lima, P. P., Liu, H.-L., Medeiros, A., Pautet, D., Riggin, D. M., São Sabbas, F., Sobral, J. H. A., Stamus, P., Takahashi, H., Taylor, M. J., Vadas, S. L., Wrasse, C.: The Spread F Experiment (SpreadFEx): Program overview and first results, Earth, Planets Space, CPEA special issue, in press, 2009.

Fritts, D. C., Vadas, S. L., Riggin, D. M., Abdu, M. A., Batista, I. S., Takahashi, H., Medeiros, A., Kamalabadi, F., Liu, H.-L., Fejer, B. G., and Taylor, M. J.: Gravity wave and tidal influences on equatorial spread F based on observations during the Spread F Experiment (SpreadFEx), Ann. Geophys., 26, 3235-3252, 2008, http://www.ann-geophys.net/26/3235/2008/.

Fritts, D. C. and Vadas, S. L.: Gravity wave penetration into the thermosphere: sensitivity to solar cycle variations and mean winds, Ann. Geophys., 26, 3841-3861, 2008, http://www.ann-geophys.net/26/3841/2008/.

Fritts, D. C., Vadas, S. A., and Yamada, Y.: An estimate of strong local gravity wave body forcing based on $\mathrm{OH}$ airglow and meteor radar observations, Geophys. Res. Lett., 29(10), doi:10.1029/2001GL013753, 2002.

Fritts, D. C. and Yuan, L.: An analysis of gravity wave ducting in the atmosphere: Eckart's resonances in thermal and Doppler ducts, J. Geophys. Res., 94(D15), 18455-18466, 1989.

Heelis, R. A., Kendall, P. C., Moffett, R. J., Windel, D. W., and Rishbeth, H.: Electrical coupling of the $\mathrm{E}$ and $\mathrm{F}$ regions and its effect on F-region drifts and winds, J. Planet. Space Sci., 22, 743-756, 1974.

Hocke, K. and Schlegel, K.: A review of atmospheric gravity waves and travelling ionospheric disturbances: 1982-1995, Ann. Geophys., 14, 917-940, 1996, http://www.ann-geophys.net/14/917/1996/.

Huang, C. S., Foster, J. C., Goncharenko, L. P., Reeves, G. D., Chau, J. L., Yumoto, K., and Kitamura, K.: Variations of low-latitude geomagnetic fiels and Dst index caused by magnetospheric substorms, J. Geophys. Res., 109, A05219, doi:10.1029/2003JA010334, 2004.

Huang. C. S., Kelley, M. C., and Hysell, D. L.: Nonlinear RayleighTaylor instabilities, atmospheric gravity waves, and equatorial spread-F, J. Geophys. Res., 98, 15631-15642, 1993.

Huang, C. S. and Kelley, M. C.: Nonlinear evolution of equatorial spread-F. 1. On the role of plasma instabilities and spatial resonance associated with gravity wave seeding, J. Geophys. Res., 101, 283-292, 1996a.

Huang, C. S. and Kelley, M. C.: Nonlinear evolution of equatorial spread-F. 2. Gravity wave seeding of Rayleigh-Taylor instability, J. Geophys. Res., 101, 293-302, 1996 b.

Huang, C. S. and Kelley, M. C.: Nonlinear evolution of equatorial spread-F. 4. Gravity waves, velocity shear, and day-to-day vari- 
ability, J. Geophys. Res., 101, 24521-24532, 1996c.

Hysell, D. L.: Radar imaging of equatorial F region irregularities with maximum entropy interferometry, Radio Sci., 31(6), 15671578, 1996.

Hysell. D. L. and Burcham, J. D.: Long term studies of equatorial spread $\mathrm{F}$ using the JULIA radar at Jicamarca, J. Atmos. SolarTeres. Phys., 64, 1531-1543, 2002.

Hysell, D. L., Chun, J., and Chau, J. L.: Bottom-type scattering layers and equatorial spread F, Ann. Geophys., 22, 4061-4069, 2004, http://www.ann-geophys.net/22/4061/2004/.

Hysell, D. L., Kelley, M. C., Swartz, W. E., and Woodman, R. F.: Seeding and layering of equatorial spread-F, J. Geophys. Res., 95, 17253-17260, 1990.

Hysell, D. L. and Kudeki, E.: Collisional shear instability in the equatorial F region ionosphere, J. Geophys. Res., 109, A11301, doi:10.1029/2004JA010636, 2004.

Hysell, D. L., Larsen, M. F., Swenson, C. M., Barjatya, A., Wheeler, T. F., Sarango, M. F., Woodman, R. F., and Chau, J. L.: Onset conditions for equatorial spread Fdetermined during EQUIS II, Geophys. Res. Lett., 32, L24104, doi:10.1029/2005GL024743, 2005.

Kamalabadi, F., Comberiate, J., Taylor, M., and Pautet, D.: Electron densities in the lower thermosphere from GUVI 1356 tomograqphic inversions in support of SpreadFEx, Ann. Geophys., in press, 2009.

Kelley, M. C.: The Earth's Ionosphere, Academic Press, San Diego, 487 pp., 1989.

Kelley, M. C., Makela, J. J., Ledvina, B., and Kintner, P. M.: Observations of equatorial spread- F from Haleakala, Hawaii, Geophys. Res. Lett., 29, 2003, doi:10.1029/2002GL015509, 2002.

Klostermeyer, J.: Nonlinear investigation of the spatial resonance effect in the nighttime equatorial F region, J. Geophys. Res., 83, 3753-3760, 1978.

Kudeki, E., Akgiray, A., Milla, M., Chau, J. L., and Hysell, D. L.: Equatorial spread-F initiation: post-sunset vortex, thermospheric winds, gravity waves, J. Atmos. Solar-Terr. Phys., 69, 2416-2427, 2007.

Kudeki, E. and Bhattacharyya, S.: Postsunset vortex in equatorial F-region plasma drifts and implications for bottomside spread F, J. Geophys. Res., 104, 28163-28170, 1999.

Lane, T. P., Reeder, M. J., and Clark, T. L.: Numerical modeling of gravity waves generated by deep tropical convection, J. Atmos. Sci., 58, 1249-1274, 2001.

Lane, T. P. and Sharman, R. D.: Gravity wave breaking, secondary wave generation, and mixing above deep convection in a threedimensional cloud model, Geophys. Res. Lett., 33, L23813, doi:10.1029/2006GL027988, 2006.

Lane, T. P., Sharman, R. D., Clark, T. L., and Hsu, H.-M.: An investigation of turbulence generation mechanisms above deep convection, J. Atmos. Sci., 60, 1297-1321, 2003.

Lanyi, G. E. and Roth, T.: A Comparison Of Mapped And Measured Total Ionospheric Electron-Content Using Global Positioning System And Beacon Satellite-Observations, Radio Sci., 23(4), 483-492, 1988.

Laughman, B., Fritts, D. C., and Werne, J.: Numerical simulation of bore generation and morphology in thermal and Doppler ducts, Ann. Geophys., 27, 511-523, 2009, http://www.ann-geophys.net/27/511/2009/.

McClure, J. P., Hanson, W. B., and Hoffman, J. F.: Plasma bubble and irregularities in the equatorial ionosphere, J. Geophys. Res., 82, 2650-2656, 1977.

McClure, J. P., Singh, S., Bamgboye, D. K., Johnson, F. S., and Kil, H.: Occurrence of equatorial $F$ region irregularities: Evidence for tropospheric seeding, J. Geophys. Res., 103, 29119-29135, 1998.

Medeiros, A. F., Buriti, R. A., Machado, E. A., Takahashi, H., Batista, P. P., Gobbi, D., and Taylor, M. J.: Comparison of gravity wave activity observed by airglow imaging at two different latitudes in Brazil, J. Atmos. Solar-Terr. Phys., 60, 647-654, 2004.

Medeiros, A. F., Fechine, J., Buriti, R. A., Takahashi, H., Wrasse, C. M., and Gobbi, D.: Response of OH, O2, and OI5577 airglow emissions to the mesospheric bore in the equatorial region of Brazil, Adv. Space Res., 35, 1971-1975, 2005.

Mendillo, M. and Tyler, A.: The geometry of depleted plasma regions in the equatorial ionosphere, J. Geophys. Res., 88, 57785782, 1983.

Meriwether, J., Faivre, M., Fesen, C., Sherwood, P., and Veliz, O.: New results on equatorial thermospheric winds and the midnight temperature maximum, Ann. Geophys., 26, 447-466, 2008, http://www.ann-geophys.net/26/447/2008/.

Oliver, W. L., Otsuka, Y., Sato, M., Takami, T., and Fukao, S.: A climatology of $\mathrm{F}$ region gravity wave propagation over the middle and upper atmosphere radar, J. Geophys. Res., 102, 1449914512, 1997.

Piani, C., Durran, D., Alexander, M. J., and Holton, J. R.: A numerical study of three- dimensional gravity waves triggered by deep tropical convection, J. Atmos. Sci., 57, 3689-3702, 2000.

Rodrigues, F. S., de Paula, E. R., Abdu, M. A., Jardim, A. C., Iyer, K. N., Kintner, P. M., and Hysell, D. L.: Equatorial spread F irregularity characteristics over São LuÍs, Brazil, using VHF radar and GPS scintillation techniques, Radio Sci., 39, RS1S31, doi:10.1029/2002RS002826, 2004.

Rodrigues, F. S., Hysell, D. L., and de Paula, E. R.: Coherent backscatter radar imaging in Brazil: large-scale waves in the bottomside F-region at the onset of equatorial spread F, Ann. Geophys., 26, 3355-3364, 2008,

http://www.ann-geophys.net/26/3355/2008/.

São Sabbas, F. T., Rampinelli, V. T., Santiago, J., Stamus, P., Vadas, S. L., Fritts, D. C., Taylor, M. J., Pautet, P. D., Dolif Neto, G., and Pinto, O.: Characteristics of sprite and gravity wave convective sources present in satellite IR images during the SpreadFEx 2005 in Brazil, Ann. Geophys., 27, 1279-1293, 2009, http://www.ann-geophys.net/27/1279/2009/.

Sekar, R. and Kelley, M. C.: On the combined effects of vertical shear and zonal electric field patterns on nonlinear equatorial spread F evolution, J. Geophys. Res., 103, 20735-20747, 1998.

Sekar, R., Suhasini, R., and Raghavarao, R.: Evolution of plasma bubbles in the equatorial $\mathrm{F}$ region with different seeding conditions, Geophys. Res. Lett., 22, 885-888, 1995.

Sentman, D. D., Wescott, E. M., Picard, R. H., Winick, J. R., Stenbaek-Nielson, H. C., Dewan, E. M., Moudry, D. R., São Sabbas, F. T., and Heavner, M. J.: Simultaneous observation of mesospheric gravity waves and sprites generated by a Midwestern thunderstorm, J. Atmos. Solar-Terr. Phys., 65, 537-550, 2003.

Sobral, J. H. A., Abdu, M. A., and Batista, I. S.: Airglow studies on the ionosphere dynamics over low latitude in Brazil, Ann. Geophys., 36(2), 199-204, 1980a. 
Sobral, J. H. A., Abdu, M. A., Batista, I. S., and Zamlutti, C. J.: Association between plasma bubble and airglow disturbances over Brazilian low latitudes, Geophys. Res. Lett., 11(7), 980-982, $1980 b$.

Sobral, J. H. A., Abdu, M. A., Takahashi, H., Taylor, M. J., de Paula, E. R., Zamlutti, C. J., and Borba, G. L.: A study of the ionospheric plasma bubbles climatology over Brazil, based on 22 years (1977-1998) of OI $630 \mathrm{~nm}$ airglow observation, J. Atmos. Terr. Phys., 64(12-14), 1517-1524, 2002.

Sobral, J. A. H., Takahashi, H., Abdu, M. A., Taylor, M. J., Sawant, H., Santana, D. C., Gobbi, D., de Medeiros, A. F., Zamlutti, C. J., Schuch, N. J., and Borba, G. L.: Thermospheric F-region traveling disturbances detected at low latitude by an OI(630 nm) imager system, Adv. Space Sci., 27, 1201-1206, 2001.

Stolle, C., Luhr, H., Rother, M., and Balasis, G.: Magnetic signatures of equatorial spread $\mathrm{F}$ as observed by the CHAMP satellite, J. Geophys. Res., 111, A02304, doi:10.1029/2005JA011184, 2006.

Swartz, W. E. and Woodman, R. F.: Same night observations of spread-F by the Jicamarca Radio Observatory in Peru and CUPRI in Alcantara, Brazil, Geophys. Res. Lett., 25, 17-20, 1998.

Takahashi, H., Taylor, M. J., Pautet, P.-D., Medeiros, A. F., Gobbi, D., Wrasse, C. M., Fechine, J., Abdu, M. A., Batista, I. S., Paula, E., Sobral, J. H. A., Arruda, D., Vadas, S. L., Sabbas, F. S., and Fritts, D. C.: Simultaneous observation of ionospheric plasma bubbles and mesospheric gravity waves during the SpreadFEx Campaign, Ann. Geophys., 27, 1477-1487, 2009, http://www.ann-geophys.net/27/1477/2009/.

Taylor, M. J. and Hapgood, M. A.: Identification of a thunderstorm as a source of short period gravity waves in the upper atmospheric nightglow emissions, Planet. Space Sci., 36, 975-985, 1988.

Taylor, M. J., Pautet, P.-D., Medeiros, A. F., Buriti, R., Fechine, J., Fritts, D. C., Vadas, S. L., Takahashi, H., and So Sabbas, F. T.: Characteristics of mesospheric gravity waves near the magnetic equator, Brazil, during the SpreadFEx campaign, Ann. Geophys., 27, 461-472, 2009, http://www.ann-geophys.net/27/461/2009/.

Taylor, M. J, Jahn, J.-M., Fukao, S., and Saito, A.: Possible evidence of gravity wave coupling into the mid-latitude $\mathrm{F}$ region ionosphere during the SEEK campaign, Geophys. Res. Lett., 25, 1801-1804, 1998.

Tsuda, T., Nishida, M., and Rocken, C.: A global morphology of gravity wave activity in the stratosphere revealed by the GPS occultation data (GPS/MET), J. Geophys. Res., 105, 7257-7274, 2000 .
Vadas, S. L. and Fritts, D. C.: Gravity wave radiation and mean responses to local body forces in the atmosphere, J. Atmos. Sci., 58, 2249-2279, 2001.

Vadas, S. L. and Fritts, D. C.: The importance of spatial variability in the generation of secondary gravity waves from local body forces, Geophys. Res. Lett., 29(20), 1984, doi:10.1029/2002GL015574, 2002.

Vadas, S. L. and Fritts, D. C.: Thermospheric responses to gravity waves arising from mesoscale convective complexes, J. Atmos. Solar Terr. Phys., 66, 781-804, 2004.

Vadas, S. L. and Fritts, D. C.: Thermospheric responses to gravity waves: Influences of increasing viscosity and thermal diffusivity, J. Geophys. Res., 110, D15103, doi:10.1029/2004JD005574, 2005.

Vadas, S. L. and Fritts, D. C.: The influence of increasing temperature and solar variability on gravity wave structure and dissipation in the thermosphere, J. Geophys. Res., TIMED special issue, 111, A10812, doi:10.1029/2005JA011510, 2006.

Vadas, S. L. and Fritts, D. C.: Reconstruction of the gravity wave field from convective plumes via ray tracing, Ann. Geophys., 27, 147-177, 2009, http://www.ann-geophys.net/27/147/2009/.

Vadas, S. L., Fritts, D. C., and Alexander, M. J.: Mechanism for the generation of secondary waves in wave breaking regions, J. Atmos. Sci., 60, 194-214, 2003.

Vadas, S. L. and Nicolls, M. J.: Using PFISR measurements and gravity wave dissipative theory to determine the neutral, background thermospheric winds, Geophys. Res. Lett., 35, L02105, doi:10.1029/2007GL031522, 2008.

Vadas, S. L., Taylor, M. J., Pautet, P.-D., Stamus, P. A., Fritts, D. C., Liu, H.-L., São Sabbas, F. T., Rampinelli, V. T., Batista, P., and Takahashi, H.: Convection: the likely source of the medium-scale gravity waves observed in the $\mathrm{OH}$ airglow layer near Brasilia, Brazil, during the SpreadFEx campaign, Ann. Geophys., 27, 231-259, 2009, http://www.ann-geophys.net/27/231/2009/.

Valladares, C. E., Hanson, W. B., McClure, J. P., and Cragin, B. L.: Bottomside sinusoidal irregularities in the equatorial $\mathrm{F}$ region, $\mathrm{J}$. Geophys. Res., 88, 8025-8042, 1983.

Vargas, F., Gobbi, D., and Takahashi, H.: Gravity wave amplitudes and momentum fluxes inferred from $\mathrm{OH}$ airglow intensities and meteor radar winds during SpreadFEx, Ann. Geophys., in press, 2009.

Woodman, R. F. and LaHoz, C.: Radio observations of F-region equatorial irregularities, J. Geophys. Res., 85, 5447-5466, 1976. 